\title{
Analytic Narratives Revisited
}

\section{Citation}

Bates, Robert, Avner Greif, Margaret Levi, Jean-Laurent Rosenthal, and Barry Weingast. 2000. Analytic narratives revisited. Social Science History 24(4): 685-696.

\section{Published Version}

http://dx.doi.org/10.1215/01455532-24-4-685

\section{Permanent link}

http://nrs.harvard.edu/urn-3:HUL.InstRepos:3219933

\section{Terms of Use}

This article was downloaded from Harvard University's DASH repository, and is made available under the terms and conditions applicable to Other Posted Material, as set forth at http:// nrs.harvard.edu/urn-3:HUL.InstRepos:dash.current.terms-of-use\#LAA

\section{Share Your Story}

The Harvard community has made this article openly available.

Please share how this access benefits you. Submit a story.

Accessibility 
Robert Bates, Avner Greif, Margaret Levi, Jean-Laurent Rosenthal, and Barry Weingast

\section{Analytic Narratives Revisited}

We welcome the animated debate raised by Analytic Narratives concerning social scientific methods and the scope of rational choice. Advocates of mathematical and rational models have long claimed they have much to tell us about situations where behavior can be quantified or where the situation under study recurs many times. However, it was thought impermissible for rational choice theories (and rational choice) to venture into the analysis of big events. Political scientists like Gary King, Robert Keohane, and Sidney Verba 
(1994) implicitly conceded the issue by concentrating on the problem of case selection when the number of cases is small but greater than one. We believe unique events are too important to leave aside, and we use rational choice, particularly game theory, as a means to study unique events.

A symposium on $A N$ is a difficult exercise. The writing of analytic narratives is still in its infancy, and the topics and aims of the volume range across disciplines and over more than a millennium. The commentaries by Daniel Carpenter, Sunita Parikh, and Theda Skocpol reflect a patience and openness that we can only applaud. Overall they agree on the merits of the enterprise but debate the nature, relevance, and extensiveness of our contribution. The question that we must therefore confront is not whether to craft analytic narratives but what constitute the standards for research in this vein.

Our critics perceptively indict us for a number of misdemeanors and perhaps even a few felonies. To most of Carpenter's, Parikh's, and Skocpol's charges we plead guilty with honor. Rather than responding to each of their criticisms individually we recognize that they fundamentally concern four issues: (1) Does $A N$ actually deliver what the introduction promises? (2) Where is the narrative? (3) Where is the analytical method? (4) How do we transform an approach to problems into a research area in social science?

\section{Moving from the Introduction to the Cases}

Is analytic narrative a method or an approach? This important question remains unresolved among the authors and consequently is evaded or inconsistently treated throughout the book. The commentary authors and other critics note that there is dissonance between the claims of the introduction and the content of the chapters. The dissonance is partly a reflection of an introduction written as a manifesto versus chapters written to advance substantive knowledge and analysis. But the dissonance runs deeper than that. Each chapter establishes that rational choice models can be used to organize a narrative of important moments in history, yet none goes very far in establishing how this can be done for moments other than those the chapter considers.

Carpenter, Skocpol, and Parikh argue convincingly that it is too early to equate analytic narrative with a method. As an approach, analytic narrative is most attractive to scholars who seek to evaluate the strength of parsimonious causal mechanisms. The requirement of explicit theorizing compels scholars 
to make causal statements and, if the model is to be fully explicated, to identify a small number of variables.

The advantages of this approach are twofold. First, it provides the researcher with some discipline. If the model is important, the narrative should not rely overmuch on factors outside the model. Hence, an explicit theory allows the scholar to distill the narrative. Second, research of this kind can proceed by iteration. A given narrative suggests a model that when explicated ought to have implications for the structure of relationships (the institutions) within which the events occurred. Those implications force the scholar to reconsider the narrative and then to reevaluate the extent to which key elements of the narrative lie outside the proposed theory. If one must appeal too often to forces outside the model, then the theory must be rejected. Analytic narrative is therefore an inductive approach that challenges both the evidence about the event of interest and theories that structure that evidence. Considered in this fashion, the volume delivers most of what the introduction promises.

A second misdemeanor relates to the audiences that the volume aims to address. As Skocpol rightly notes, the introduction is bold and ambitious, while the chapters are narrower in scope and sometimes neglect important literatures. We are pleased that Carpenter, Skocpol, and Parikh perceive our work as relevant beyond the scope that we have given it and thus demand greater intersection with other scholars. However, the combination of the breadth of some of our topics and their condensation from larger projects sometimes leads us to neglect arguments that are less significant for the specific focus of the $A N$ chapters. To take a specific example, Rosenthal wrote his $A N$ chapter for economic historians, who tend to overemphasize the distinctions between early modern England and France and to downplay the fundamental fiscal conflicts that animated both societies. It is true, as Skocpol argues, that the political and economic divergence between England and France has attracted a lot of attention beyond the authors Rosenthal cites, but these scholars emphasize problems distinct from those Rosenthal seeks to explain.

Nonetheless, if analytic narrative is to mature as an approach, it must follow an inclusive path, one that favors a dialogue with scholars of other ideological and methodological vantage points. To the extent that $A N$ leads to a conversation not just over the inclusion of explicit theorizing in a narrative approach but over the substantive conclusions of the chapters, then we 
have succeeded in furthering interdisciplinary dialogue. These articles leave us with a greater awareness of our responsibility in maintaining and extending this dialogue.

\section{Narrative and Aesthetics}

What, then, does research such as ours require? Where is the narrative? What constitutes the analytic?

Carpenter emphasizes the narrative side and suggests that beyond the models, the chapters lack the rhythm of a narrative. The models, he argues, interfere with the story and break the suspense, the uncertainty that would hold the attention of the reader. While our approach to narration may be controversial, we want to emphasize the difference between aesthetics and efficacy. Storytelling does not always imply suspense. When we pick up a mystery novel from a series with a recurring hero we know the hero will almost invariably (a) survive and (b) solve the mystery. Hence, if those two questions were key to keeping our attention, we would never even begin the novel. What keeps us turning the pages, rather, is the question of what dangers the hero faces and how the mystery will be solved. Keeping the reader alert through suspense is a matter of aesthetics, not efficacy. Suspense and intrigue seem unlikely to be of import in our chapters, since most of our readers know that the Civil War occurred, that the English rather than the French had a Glorious Revolution, or that mass conscription became an issue for modernizing nineteenth-century states. Readers may not know of the International Coffee Organization, and they may not know just how powerful and rich Genoa once was. But the quality of narrative in social science should not depend on what the reader knows any more than it did in classical tragedy. Carpenter's criticism underscores how analytic narratives involve a trade-off between the level of detail included and explicit models. The inclusion of an explicit model highlights the causal structure, which is precisely what we are interested in and what we want to better understand.

Perhaps this reaction to Carpenter leans too much on the specifics of suspense and not enough on his more general point-that the explicit theory component of an analytic narrative necessarily forgoes many of the routine literary devices that help make many standard narratives compelling. To this we plead guilty. Our narratives may hold the reader less ably, but we believe 
that the analytic rigor and clarity as to the mechanisms underlying historical change far outweigh these costs. Indeed, we go further. The net costs run in just the opposite direction from that emphasized by Carpenter. Rhetorical and dramatic skills sometimes mask bad history. When historians have no idea why something happened and use drama to move the story along, this is a misuse of drama. For example, Weingast must explain why S. A. Douglas and other Democratic leaders gave in to the South in the winter of 1853-54 and agreed to repeal the Missouri Compromise in the Kansas-Nebraska Act of 1854. Their action represented the biggest political blunder for the Democrats between the election of Andrew Jackson in 1828 and their defeat by Abraham Lincoln in 1860. Why did they do it? Historians have no answer to this question; they never even ask it. They describe late-night secret meetings rather than offer an explanation.

Our critics raise other issues with aesthetic overtones. Skocpol, for example, faults us for a lack of elegance in highlighting our working approach, and Parikh, especially in her verbal presentation, has taken us to task for failing to provide more of the sense of time and place that brings a narrative to life. Since the purpose of this book, as distinct from the elaborated volumes several of our chapters draw upon, is to clarify the method, the skeleton is the message. Our idea of narrative has always included rich detail; several of us engage in fieldwork, and all delve deeply into archives and historical records. But, again, there is a trade-off, particularly in chapter-length pieces, between conveying the richness of what we have learned and the causal argument. The art of combining modeling with the smells and sounds of the events we are explaining may still elude us, but we value the combination. We hope that future scholars will be more successful than we seem to have been, at least in this small book.

The commentators raise a number of substantive issues. Skocpol correctly insists that we get the institutions and historical context right. She particularly takes Levi and Weingast to task on this score. Levi can certainly be faulted for ignorance of James Geary's excellent book (1991) and for failure to report the votes in Congress, but she is not guilty of mis-specifying the American institutions. The very point of her discussion is to explain the abolition of commutation and the retention of substitution, and the explanation lies solidly in the particular institutional features of the United States, especially its localism and lack of extensive bureaucracy. There is not even a dis- 
agreement over the extent of actual class inequity. For Levi it is the perception, not the structural reality, of class discrimination that drives the analysis and causes institutional change. Skocpol's question is different; her concern is the relative fairness of Civil War recruitment versus that of later wars.

As Skocpol observes, Weingast's chapter ignores a great many factors leading to the Civil War. The chapter focuses on the balance rule in large part because he believes this underlies many of the other elements that historians view as independent factors. The chapter argues, for example, that the sequence of disastrous choices by Democrats-including the infamous Kansas-Nebraska Act, which helped destroy the second party system and set the stage for the rise of the Republicans - all reflected the unappreciated logic compelling them to attempt to restore sectional balance. The critical feature of the model is not congressional voting - on which rational choice theorists are sometimes fixated-but the fact that balance gave the South and hence slaveholders a veto over national policy. This veto helped maintain the Union for several generations, and its absence helped bring on the Civil War. Skocpol errs, however, when she criticizes Weingast for ignoring that actors can be "blindsided by massive contextual shifts." His argument about the Democrats' failure in the $1850 \mathrm{~s}$ draws on exactly such a shift: they were blindsided by what we now clearly see as the end of the second party system, something they only dimly perceived at the time. Indeed, part of the reason we so clearly understand this shift is that, in ignorance, they provoked such an extraordinary political reaction.

Skocpol's criticisms reflect the ongoing controversy between rationalists and macrostructuralists as much as insights into particular flaws in the arguments. Parikh correctly takes us to task for treating the two approaches as complementary rather than emphasizing their distinctive contributions and clarifying the appropriate scope of each approach. If we had done as Parikh requests, then some of the basis for Skocpol's criticisms would have disappeared.

Carpenter raises an equally important and related question that we did not confront: what is the scope of an analytic narrative? In effect he raises two questions: one about subject area (can an analytic narrative be used to elucidate political situations where voting occurs?) and one about method. We strongly endorse the position that analytic narratives should have no boundaries with respect to subject or evidence. We see no good reason to limit ana- 
lytic narratives to areas of behavior where people possess the franchise or to neglect voting information when it is relevant to the processes one seeks to understand. With respect to method, one should not dwell overmuch on the limits of analytic narratives as represented by the limited scope of the chapters in the book. First, our restriction of models to extensive form games enhances the unity of the volume but limits the range of issues we address. There is still a vast set of problems susceptible to analysis, and an even larger set if one is willing to go beyond game theory to include other formal or abstract theorizing. Second, we focus our research on issues where we believe that problems of randomness or contingency are not too severe. To take an example, in Levi's chapter governments solved their conscription problem in the face of uncertainty about the occurrence of war and only partial information about the reaction of draftees to changes in the rules. Because the response of draftees requires coordination, one could imagine that the world of conscription is unstable, with countries shifting the mechanisms they use to staff their armies from one year to the next based on fluctuating social norms of resistance. Had that been the case, Levi would probably not have been drawn to write on the subject as an analytic narrative. She could have treated each year independently and thus used traditional means to develop and test the model of soldier procurement. For the purposes of our volume, we focused on cases where there is some but hardly complete certainty in the path of history, cases where the model helps us understand what is likely to happen. We emphasize, however, that nothing about the method limits us to cases of certainty or modest uncertainty. Extensive form games have long been used to study settings of high uncertainty and contingency.

In fact, contingency is extremely important to our approach; in its absence there is little room for strategy. To take another example, one could argue that the Glorious Revolution was the product of contingency, since it was the outcome of at least four different processes that came together in early 1688: a fundamental fiscal conflict, a new heir to the throne, a threat to disenfranchise most of the elite, and the marriage of the king's possible successor to the ruler of the Low Countries. The argument could then proceed to say that Rosenthal's model does not elucidate what happened in 1688, for it only encapsulates the first of these four processes. Further, one could argue that if a single one of the four had not been in place, there would have been no Glorious Revolution, and England would have evolved a different political 
regime. In particular, one can easily imagine that absent William of Orange's claim to the throne, England would have ended up with a Catholic sovereign and an absolutist government. Nonetheless, it is worthwhile to put a primary emphasis on the fiscal conflict, for it was concern over fiscal independence that motivated James II to tamper with Parliament, and it was concern over securing British fiscal resources for his coming conflict with Louis XIV that compelled William to intervene in England. Such a primary emphasis does not rule out contingency. Indeed, had there been no contingency, it is impossible to make consistent the behavior of James II in 1687-88 and the behavior of the elite in 1688-89. If James was sure that the elite would get rid of him if he acted to disenfranchise them, he would not have tried to reshape Parliament in 1687. Similarly, if the elite had been sure that it would lose an armed conflict to James, no revolt would have occurred in 1688. In other words, the revolution could only have occurred because its outcome was uncertain.

The approach stands in sharp opposition to views of history that would make the outcomes of events totally systematic or unsystematic in the extreme. Our ideological position holds that understanding the institutional context within which events occur helps us understand both how certain events may happen and why they may happen. This is an ideological position rather than a methodological position because there is nothing per se in game theory that rules out complete uncertainty - and proofs are few and far between. Yet if Greif's chapter is a success, it is because the model helps him to understand why the political equilibrium of the Podesta solved some important problems for Genoa and why the Genoese were particularly likely to adopt such a solution rather than an alternative (constitutional government or autocracy).

In all cases we have chosen to privilege parsimonious models, ones where the number of exogenous factors were a half dozen or less, so as to better understand how changes in their value can affect the institutional equilibrium. This affects the narrative by reducing the importance of other variables for the story. For instance, for Bates one sort of uncertainty was critical: movements in the price of coffee. On the other hand, variations in U.S. economic activity - however important they may be to the world economy were much less salient. All narratives have to have an anchor (or set of anchors). Analytic narratives make their theoretical anchor more explicit (and 
thereby easier to criticize) than other accounts do. The requirement of a formal model in no way limits the scope of uncertainty or contingency, nor does it obligate anyone to focus on game-theoretic models. In sum, if our first mea culpa was that we have been too ambitious, our second is that in other dimensions we have been too restrictive.

\section{Models in Social Science}

How do we transform an approach to problems into a research area in social science? We argue that analytic narrative is a useful approach in a large number of settings. Parikh observes - as have many others - that save for the opportunism of coining a phrase, the book may be less novel than it appears. We and other scholars have been creating analytic narratives for some time. Yet, to Parikh's dismay, there are few things worse than a bad analytic narrative. It is therefore critical, she argues, that there be some rules as to how an analytic narrative should be constructed. Carpenter echoes this sentiment. How is one to teach analytic narrative, and how is it to spread in the social sciences, if it cannot be codified? In keeping with our admission that we seek to characterize an approach rather than a method, we can only formulate a few guidelines.

1. Avoid the use of off-the-shelf models unless they demonstrably enhance the explanatory project. While political scientists in particular are fond of appealing to one of a small number of models (prisoner's dilemma, battle of the sexes, principal agent with moral hazard, principal agent with adverse selection), these models are often very uninformative. Their analysis depends on the context; each of these models can lead to either an efficient solution or an inefficient one, to a problem solved or to a problem not solved. By understanding the context, the research scholar can build a model that is more appropriate in that it captures institutional constraints. The constraints in turn will alert us to what set of outcomes is possible, to how the particular problem faced by a society can be solved.

2. Take the theory seriously. Building a model that reflects the set of historical circumstances in which the event of interest is embedded requires that the researcher do as much with the theory as possible. In particular, the model should have two sets of results that allow the scholar to deepen the investiga- 
tion. First, there should be comparative static results that suggest what might have happened in different circumstances; these results are critical for comparative research. Second, the model contains assumptions that can be challenged to gain further insight. A third set of issues applies to game-theoretic models: one must pay careful attention to the off-the-equilibrium-path behavior - what happens along the paths not taken often determines what paths are taken. Because off-the-path behavior anchors the equilibrium, we must have a very good sense of what the actors in the event we study think of what will happen when things go wrong.

3. Take the narrative itself seriously in the sense of getting the details as correct as possible and of providing richness to the extent appropriate. We are not advocating just abstract models with examples but the kind of work good economic and political historians do. The emphasis is on explanation and evidence, but it is essential to actually capture the key components of the particular problem, place, and time under consideration. This may require a combination of quantitative and qualitative evidence; it definitely requires enough context to adequately account for the central strategic decisions.

4. Iterate between theory and data. While rational choice proponents often emphasize the importance of deduction and hypothesis testing, we believe that most social science research - including rational choice scholarship - is iterative and inductive. We begin all of our research with some basic information and some theoretical priors, then we accumulate new information and formulate new models. In his chapter, Bates details this process, moving from a model of oligopoly to a model of political economy. Such a radical change is evidence of how much we can learn by starting from one clearly articulated vantage point, confronting it with the evidence, and then selecting a new one. Iteration between theory and data also has implications for how we conduct research. Each new model we adopt should be consistent with what we know and should explicate what new data we still need. Accepting the iterative process demands that we shed some of the arrogance that rational choice proponents have about deductive reasoning and its superiority. When constructing the theory, social scientists often already know a lot about the data/problem/case that they study. While this is true generally in social science, it is even more obvious in an approach like analytic narrative, where the theory must be embedded in the narrative. 


\section{Conclusion}

By its very nature $A N$ is a perilous enterprise. Our essays implicitly argue that we all carry an analytic narrative around with us in our research and that making it explicit will help the research. We had hoped that the chapters would demonstrate that analytic narrative has value two ways. First, because of its very sparseness, the model forces us to choose a simple "dominant" causal framework and thus clarify the narrative. Second, an explicit framework helps us to detect dissonance in the evidence, those facts or relationships that do not fit with the model and therefore deserve attention. The symposium consists of scholars interested in comparative analysis and big events, half of the audience that we sought to attract. The other half are analytically minded economists and political scientists. The symposium authors surprised us with their willingness to enter into a dialogue over issues of substance and form. Daniel Carpenter, Sunita Parikh, and Theda Skocpol's critiques encourage us to raise our standards further. They rightly insist that we must do more to define the craft of analytic narrative, to extend it beyond a set of historical cases, and to forge links with alternative approaches. For each of these critiques we thank them.

\section{Notes}

Robert H. Bates is Eaton Professor of the Science of Government at Harvard University and Faculty Fellow of the Center for International Development. Among his recent books are Open Economy Politics (Princeton 1999) and Prosperity and Violence (W. W. Norton 2000). Avner Grief is professor of economics at Stanford University and a MacArthur Fellow. He is completing "The Institutional Foundations of States and Market: Genoa and the Maghribi Traders." Margaret Levi is professor of political science and Harry Bridges Chair at the University of Washington, Seattle. Her books include Of Rule and Revenue (California 1988) and Consent, Dissent, and Patriotism (Cambridge 1997). Jean-Laurent Rosenthal is professor of economics at UCLA. His books include The Fruits of Revolution: Property Rights, Litigation, and French Agriculture, 1700-1870 (California 1992) and Priceless Markets: The Political Economy of Credit in Paris, 1660-1869 (Chicago 2000). Barry R. Weingast is a Senior Fellow at the Hoover Institution and the Ward C. Krebs Family Professor and chair at the Department of Political Science at Stanford University.

Bates (1997) and Levi (1997) have already published their book-length manuscripts. Weingast and Greif are working on theirs. Rosenthal's article here was distinct from the work in the manuscript he has been completing. 
696 Social Science History

\section{References}

Bates, R. H. (1997) Open Economy Politics: The Political Economy of the World Coffee Trade. Princeton, NJ: Princeton University Press.

Geary, J. W. (1991) We Need Men: The Union Draft in the Civil War. Dekalb: Northern Illinois University Press.

King, G. R. Keohane, and S. Verba (1994) Scientific Inference in Qualitative Research. Princeton, NJ: Princeton University Press.

Levi, M. (1997) Consent, Dissent, and Patriotism. New York: Cambridge University Press. 